\title{
Clinical and Haemodynamic Effects of Bi-Level Positive Airway Pressure in Patients with Decompensated Heart Failure
}

\author{
SOHEIR M.K. AHMED, M.D.*; HATEM H.M. MAGHRABY, M.D.**; SAMIR EL-HADIDY, M.D.*** and \\ AHMED S.A. MAHFOUZ, M.Sc.*
}

The Departments of Internal Medicine*, Anaesthesia \& Intensive Care**, Faculty of Medicine, Assiut University, Assiut and Department of Critical Care Medicine***, Faculty of Medicine, Cairo University

\begin{abstract}
Background: Heart failure is a growing problem worldwide with high degree of morbidity and mortality especially in those with dilated cardiomyopathy. We hypothesized that noninvasive bi level positive airway pressure ventilation (BIPAP) could play a crucial role in those patients.

Aim of Study: To study the effect of Non Invasive bi-level positive air way pressure (BIPAP) ventilation on the clinical, hemodynamic parameters in patients with heart failure NYHA class 3-4 due to dilated cardiomyopathy.

Patients and Methods: Forty adult patients, (18-83 years old) of both sex with decompensated heart failure and dilated cardiomyopathy ( $\mathrm{LVEF}<35 \%$ ) were included in the study, they were recruited from both emergency department and critical care unit of internal medicine department, Assiut university hospital. They were divided into two groups: Group A (20 patients) received the standardmedical therapy for heart failure and supported Noninvasive positive pressure ventilation (NIV) through BIPAP, while group B (20 patients) received only the standard medical therapy for heart failure with simple mask oxygen therapy.
\end{abstract}

Results: There was a statistically significant improvement in dyspnea, tachypnea $\left(p=0.041^{*}, 0.031\right)$ in the group A compared to the group B, Meanwhile there was insignificant improvement in tachycardia, and hypotension in group A compared to group B. All patients were cooperative, and only one patient from each group needed intubation, deteriorated rapidly, and died.

Conclusion: In our study, adding Noninvasive Bi Level Positive airway ventilation (BiPAP) to conventional medical treatment improved clinical, hemodynamic, parameters in dilated cardiomyopathy patients with decompensated heart failure. We concluded, "BiPAP is not only a safe adjuvant to the conventional treatment but also, it can be more advantageous in the management of patients with dilated cardiomyopathy with decompensated heart failure".

Key Words: BIPAB - Dilated cardiomyopathy - Heart failure.

Correspondence to: Dr. Soheir M.K. Ahmed, E-Mail: omarsoheir@yahoo.com

\section{Introduction}

HEART failure is a disease with high incidence and prevalence in the population. The costs with hospitalization for decompensated heart failure reach approximately $60 \%$ of the total cost with heart failure treatment, and mortality during hospitalization varies according to the studied population, and could achieve values of $10 \%$ [1]

Decompensated heart failure (DHF) is a clinical syndrome in which a structural and/or functional change in the heart and leads to its inability to eject and/or accommodate blood, which causing a functional limitation and requiring immediate therapeutic intervention [2]. The initial objective of the treatment of DHF is to achieve hemodynamic and symptomatic improvement [3].

Many patients may improve with conventional medical treatments using simple oxygen mask, diuretics, and vasodilators. However, despite endotracheal intubation may be complicated by aspiration, laryngeal injury and others [4] but "invasive" mechanical ventilatory support (through endotracheal intubation) is required and may be preferable if respiratory distress cannot be alleviated quickly.

Positive airway pressure is said to have its own Preferential hemodynamic effects in patients with chronic heart failure as it increases intrapleural and pericardial pressure, which decreases venous return (i.e., preload) and transmural myocardial pressure (i.e., afterload).Subsequently, there are reductions in ventricular diameter and functional mitral regurgitation and improvements in cardiac output, besides improvements in pulmonary mechanics include greater alveolar recruitment with decreased shunting and increase inpulmonary compliance [5] 
Bi-level positive airway pressure (BiPAP), a non-invasive ventilation modality (NIV) provides two different levels pressure, higher airway pressures are applied during inspiration and lower during expiration. A number of studies have demonstrated beneficial effects of BiPAP in acute asthma, and severe pneumonia, With BiPAP, the inspiratory pressures (IPAP) must be set separately from the expiratory pressures (EPAP). Generally, the IPAP settings start at $8-10 \mathrm{~cm} \mathrm{H} 2 \mathrm{O}$, and can range from 4 to $24 \mathrm{~cm} \mathrm{H} 2 \mathrm{O}$. The EPAP settings typi-callystart at $2-4 \mathrm{~cm} \mathrm{H} 2 \mathrm{O}$, and range from 2 to $20 \mathrm{~cm} \mathrm{H} 2 \mathrm{O}$.

These initial settings aim to optimize patient tolerance and Discontinuing NIV generally requires a "weaning" period. During this time, nearby observation of the patient is essential. Indications for weaning the NIV include general patient stability, consistent oxygenation $>90 \%-92 \%$ with $4 \mathrm{~L} /$ minute (or less) of supplemental oxygen, and a respiratory rate $<25$. The weaning process of decreasing the pressure settings should generally parallel the process by which pressures increased: If several increments of increase were used, the reverse should hold true for the weaning process. Consider resuming or increasing the NIV if the respiratory rate increases to $>30$, oxygen saturation drops below $90 \%$ (despite $4 \mathrm{~L} /$ minute of oxygen), or if the $\mathrm{PaCO} 2$ increases by at least $5 \mathrm{mmHg}$. Sudden or severe deteriorations warrant consideration of conventional intubation techniques and mechanical ventilation [6]

\section{Patients and Methods}

In a prospective randomized controlled interventional study, Forty adult patients, aged between 18-83 years, of both sexes, and normal body weight, $(\mathrm{BMI}=25-35)$. This study was approved by the local Ethics Committee, Faculty of Medicine, Assiut University during 2017. All the patients or one of their accompanies provided oral and written consents. Patients were admitted to the Critical Care Unit of Internal Medicine Department, Assiut University Hospital, by manifestation of decompensated heart failure (NYHA III-IV, ACC/AHA stage C-D) [7,8] such as dyspnea, PND, orthopnea, raised JVP, bilateral basal crackles, laterally displaced apical impulse, bilateral lower limb edema due to dilated cardiomyopathy ( $\mathrm{EF}=\mathrm{LVEF}<35 \%)$.

\section{Exclusion criteria:}

- Any chest disease (Severe acute or chronic airway or parynchymal diseases).

- Valvular heart disease other than functional regurge.
- Ventricular arrhythmias.

- Immediate indication for tracheal intubation [10]: (=Rescue ventilator support in case of failed NIV):

- Cardiogenic shock: Systolic blood pressure $<90 \mathrm{mmHg}$.

$-\mathrm{SpO}_{2}<80 \%$ on $\mathrm{FIO} 2=1$.

- PH less than 7.25, PCO 2 more than $55 \mathrm{~m} \mathrm{mHg}$.

- Altered mental state.

- Cardiac or respiratory arrest.

\section{Patients were divided into:}

Group A (Study group, $n=20$ ): Patients received the standard medical therapy for heart failure (such as diuretics, ACE inhibitor, and digoxin) and supported NIV through BIPAP.

Group B (Control group, $n=20$ ): Included patients who received the standard medical therapy for heart failure only with the conventional oxygen therapy through oxygen mask.

Randomization was done by computer-generated table, all participants were subjected to full history taking and full physical examination including vitals, chest and meticulous cardiovascular examination. ECG monitoring for any new changes, or arrest, and Plain Chest X-ray for presence of increased cardiothoracic ratio, prominent bronchovascular markings.

\section{Treatment modalities:}

Group (A) patients received the standard medical therapy for heart failure (like that for group B) in the form of diuretics (furosemide $20-240 \mathrm{mg}$ daily, spironolactone $25-50 \mathrm{mg}$ daily), angiotensine converting enzyme inhibitors (ramipril $2.5-10 \mathrm{mg}$ daily) and vasodilators (if needed such as nitroglycerin ...) plus supported non-invasive ventilation through BIPAP. The BIPAP use was in intermittent sessions each of 2 hours for 2 consecutive days. The mean duration of BIPAP use was 8 hours daily. The first session was during the first 4 hours of starting the therapy. Group (B) patients received the standard medical therapy for heart failure (like that for group A), plus oxygen venture-mask $40 \%$, and changed according to Sao 2 for 48 hour.

- Rescue ventilatory support: Failure of oxygen therapy or Non Invasive BIPAP therapy inany patient is an indication for immediate intubation and invasive mechanical ventilation as mentioned above.

- Rescue circulatory support: In case of hemodynamic instability, such as decreased SBP $<90 \mathrm{mmhg}$, or $25 \%$ of basic reading, we will 
initiate dopamine or dobutamine inotropic support ( \pm isosorbide dinitrite).

\section{Ventilator setup:}

- The ventilator used was "Puritan Bennett 840 Ventilator System".

- Bi Level mode.

- The patients received ventilation through oronasal mask.

- The high pressure started at $8-10 \mathrm{~cm} \mathrm{H} 2 \mathrm{O}$ (raised to $16 \mathrm{~cm} \mathrm{H}_{2} \mathrm{O}$ ).

- The low pressure started at $4-5 \mathrm{~cm} \mathrm{H} 2 \mathrm{O}$ (elevated to $8 \mathrm{~cm} \mathrm{H}_{2} \mathrm{O}$ ).

Fraction of inspired oxygen ( $\left.\mathrm{FiO}_{2}\right)$ 0.4.

For both groups: Vital signs were recorded at baseline, after 4 hours and after 48 hours.

\section{Statistical analysis:}

All analyses were performed using the IBM SPSS 20.0 software. The data were tested, at first, for normality using the Shapiro-Wilk test, and for homogenecity variances prior to further statistical analysis. Categorical variables were described by number and percent $(\mathrm{N}, \%)$, while the continuous variables were described by mean and standard deviation (Mean, SD, Median). Chi-square test and fisher exact test used to compare between categorical variables, while compare between continuous variables by $t$-test for normally distributed data and Mann Whitney U for abnormally distributed data. A two-tailed $p<0.05$ was considered statistically significant.

\section{Results}

There was no statistically significant differences between both groups as regard to the age, gender, and co-morbidities, as shown in Tables $(1,2)$.

While there was a statistically significant reduction in the length of stay in the group A patients versus group $B(4.6 \pm 0.3$ vs. $5.1 \pm 0.8$ days), with a $p$-value $=0.013($ Table 2$)$.

Despite there was no statistically significant difference between the two groups of the study, as regarded to dyspnea after 48 hours $(p=0.246)$, but there was significant improvement in tachypnea in group A; as well as there was improvement within each group using paired $t$-test, (Table 3 ).

After 48 hours, there was statistically significant improvement in the hemodynamics and clinical parameters compared to the baseline readings in both groups.
In group A, as regard to: $\mathrm{SBP}(109.64 \pm 16.23$ vs $123.21 \pm 19.77$ ) with a percent of change $11 \%$, DBP $(67.5 \pm 8.49$ vs $77.5 \pm 8.93)$ with a percent of change $12.9 \%$, and HR $(81 \pm 9.24$ vs $96.07 \pm 16.07)$ with a percent of change $15.7 \%$, dyspnea was still in two patient $2 / 20(10 \%)$ and completely improved in $15 / 20(75 \%)$ patient, while there was improvement in tachypnea (from18-50 (24) to 16-30 (19) with a percent of change $=36.8 \%$ after 48 hours. (Tables 3,4).

Similarly, in group B, there was a statistically significant difference was found after 48 hours of medical treatment, as regard to the SBP (107.86 \pm 20.35 vs $112 \pm 24.87$ ) with a percent of change $4.1 \%$, DBP $(68.93 .93 \pm 14.7$ vs $71.79 \pm 14.09)$ with a percent of change $4.0 \%$, and HR $(88.71 \pm 8.76$ vs $100.57 \pm 22.47$ ) with a percent of change $11.8 \%$, dyspnea after 48 hours, was still in three patients $3 / 20(15 \%)$ and completely improved in $10 / 20$ $(50 \%)$ patient, while there was improvement in tachypnea from 18-34 (22) to a 14-38 (18) with a percent of change $=25.6 .3 \%$ after 48 hours (Tables $3,4)$.

When compared both groups, there was statistically significant difference between both groups as regard to the percentage changes of SBP, and DBP, with $p$-values $(=0.033,0.022)$ respectively, without a significant differences between that of the HR ( $p=0.099)$ (Table 4).

All patients were cooperative and accepted the line of treatment, especially those received the NIPPV through bi level positive pressure ventilation (group A).

There was no statistically significant difference between both groups regarding the incidence of mortality, during the study. However, one patient of each group died because of cardiogenic shock, within two days, after the end of the study. The patient from group A was admitted with decompensated heart failure and blood pressure of (100/65), after 2 days the patient became hypotensive, so that, we stopped diuretics and added inotropic and vasoactive supporting measures, eventually he was intubated and mechanically ventilated for 3 days then died in asystole. The patient from group B was admitted with decompensated heart failure, jaundice and blood pressure was 95/65. Similarly, the patient became hypotensive within 2 days. Despite of stopping diuretics and adding inotropic and vasoactive measures, but he was intubated and mechanically ventilated for 2 days then died. 
Table (1): Demographic data.

\begin{tabular}{llll}
\hline & \multicolumn{1}{c}{$\begin{array}{c}\text { Group A } \\
(\mathrm{n}=20)\end{array}$} & $\begin{array}{c}\text { Group B } \\
(\mathrm{n}=20)\end{array}$ & $p$-value \\
\hline $\begin{array}{l}\text { Age (Years): } \\
\text { Mean } \pm \text { SD }\end{array}$ & $60.29 \pm 11.35$ & $54.07 \pm 13.93$ & 0.207 \\
Gender: & & & \\
$\quad$ Male: $\mathrm{n}(\%)$ & $15(75 \%)$ & $14(70.0 \%)$ & 0.723 \\
Female: $\mathrm{n}(\%)$ & $5(25 \%)$ & $6(30.0 \%)$ & \\
\hline
\end{tabular}

Group A=BIPAP ventilation plus medical treatment. Group $\mathrm{B}=$ Only medical treatment plus simple mask oxygen.

Unpaired $t$-test for comparison between both groups. $p$-value $<0.05 \%$ is considered significant*.

Table (2): The Co-morbidities and length of hospital stay.

\begin{tabular}{lccc}
\hline Co-morbidities & $\begin{array}{c}\text { Group A } \\
(\mathrm{n}=20)\end{array}$ & $\begin{array}{c}\text { Group B } \\
(\mathrm{n}=20)\end{array}$ & $p$-value \\
\hline DM+HTN+IHD & 0 & 4 & \\
DM+IHD & 4 & 1 & \\
IHD+ HTN & 0 & 1 & \\
DM & 1 & 0 & \\
HTN & 1 & 0 & \\
IHD & 3 & 3 & \\
Thyrotoxicosis & 1 & 0 & \\
No of patients with & $10=(50 \%)$ & $9=(45 \%)$ & 0.751 \\
$\quad$ co-morbidities & & & \\
In-hospital stay (days) & $4.6 \pm 0.3$ & $5.1 \pm 0.9$ & $0.013^{*}$ \\
\hline
\end{tabular}

Group A=BIPAP ventilation plus medical treatment.

Group $\mathrm{B}=$ Only medical treatment plus simple mask oxygen. Unpaired $t$-test for comparison between both groups.

$p$-value $<0.05 \%$ is considered significant*.

Table (3): Respiratory changes.

\begin{tabular}{|c|c|c|c|}
\hline & $\begin{array}{c}\text { Group A } \\
(\mathrm{n}=20) \\
\text { No. }(\%)\end{array}$ & $\begin{array}{c}\text { Group B } \\
(\mathrm{n}=20) \\
\text { No. }(\%)\end{array}$ & $\begin{array}{c}p- \\
\text { value }\end{array}$ \\
\hline \multicolumn{4}{|l|}{ Dyspnea after } \\
\hline \multicolumn{4}{|l|}{4 hours: } \\
\hline Still & $4(20 \%)$ & $8(40 \%)$ & $0.041 *$ \\
\hline Little improved & $11(55 \%)$ & $12(60 \%)$ & \\
\hline $\begin{array}{l}\text { Completely } \\
\text { Improved }\end{array}$ & $5(25 \%)$ & $0(0 \%)$ & \\
\hline \multicolumn{4}{|l|}{ Dyspnea after } \\
\hline \multicolumn{4}{|l|}{48 hours: } \\
\hline Still & $2(10 \%)$ & $3(15 \%)$ & 0.246 \\
\hline Little improved & $3(15.0)$ & $7(35 \%)$ & \\
\hline $\begin{array}{l}\text { Completely } \\
\text { Improved }\end{array}$ & $15(75.0)$ & $10(50 \%)$ & \\
\hline \multicolumn{4}{|l|}{$R R:$} \\
\hline Baseline & $33.21 \pm 11.12$ & $25.43 \pm 4.77$ & $0.023 *$ \\
\hline After $4 \mathrm{~h}$ & $18-50(24)$ & 18-34 (22)\# & 0.091 \\
\hline$\%$ of change & 17.0 & 10.4 & $0.031 *$ \\
\hline After $48 \mathrm{~h}$ & 16-30 (19)\# & 14-38 (18)\# & 0.325 \\
\hline$\%$ of change & 36.8 & 25.6 & $0.016^{*}$ \\
\hline
\end{tabular}

Group A=BIPAP ventilation plus medical treatment.

Group $\mathrm{B}=$ Only medical treatment plus simple mask oxygen.

Unpaired $t$-test for comparison between both groups.

$p$-value $<0.05 \%$ is considered significant*.

\# Statistically significant difference in comparison with baseline $(p<0.05)$ using paired $t$-test.
Table (4): Hemodynamic changes among patients of both study groups.

\begin{tabular}{llll}
\hline & \multicolumn{1}{c}{$\begin{array}{c}\text { Group A } \\
\text { Mean } \pm \text { SD }\end{array}$} & \multicolumn{1}{c}{$\begin{array}{c}\text { Group B } \\
\text { Mean } \pm \text { SD }\end{array}$} & $\begin{array}{c}p- \\
\text { value }\end{array}$ \\
\hline SBP: & & & \\
Baseline & $123.21 \pm 19.77$ & $112.5 \pm 24.87$ & 0.218 \\
After 4h & $117.14 \pm 19.39$ & $111.43 \pm 20.98$ & 0.461 \\
\% of change & 4.9 & 1.0 & 0.087 \\
After 48h & $109.64 \pm 16.23$ & $107.86 \pm 20.35$ & 0.799 \\
$\%$ of change & 11.0 & 4.1 & $0.033^{*}$ \\
DBP: & & & \\
Baseline & $77.5 \pm 8.93$ & $71.79 \pm 14.09$ & 0.211 \\
After 4h & $73.21 \pm 8.23$ & $71.07 \pm 11.47$ & 0.575 \\
$\%$ of change & 5.5 & 1.0 & $0.042^{*}$ \\
After 48h & $67.5 \pm 8.49$ & $68.93 \pm 14.7$ & 0.755 \\
$\%$ of change & 12.9 & 4.0 & $0.022^{*}$ \\
HR: & & & \\
Baseline & $96.07 \pm 16.07$ & $100.57 \pm 22.47$ & 0.547 \\
After 4h & $88.57 \pm 14.55$ & $90.43 \pm 12.75$ & 0.722 \\
$\%$ of change & 7.8 & 10.1 & 0.727 \\
After 48h & $81 \pm 9.24$ & $88.71 \pm 8.76$ & $0.032^{*}$ \\
$\%$ of change & 15.7 & 11.8 & 0.099 \\
\hline
\end{tabular}

Group A=BIPAP ventilation plus medical treatment.

Group $\mathrm{B}=$ Only medical treatment plus simple mask oxygen.

Unpaired $t$-test for comparison between both groups.

$p$-value $<0.05 \%$ is considered significant*.

$\mathrm{SBP}=$ Systolic blood pressure. DBP =Diastolic blood pressure $\mathrm{HR}=$ Heart rate.

\section{Discussion}

In our study we found significant differences between patients who received BIPAP plus medical treatment (group A) and those received medical treatment only plus intermittent oxygen mask (group B) as regard to the clinical and heamodynamic changes with more improvement of those parameters in group A. As regard to dyspnea, group A also, showed dramatic and rapid improvement of dyspnea after 4 hours from starting treatment, but both modalities of treatment became nearly equally effective after 48 hours. Improvement of dyspnea was consequently accompanied with significant improvement in respiratory ratet between the two groups. Respiratory rate was decreased in both groups but significantly in group A after 4 hours from baseline and after 48 hours from baseline despite there was significant difference between both groups as regard baseline respiratory rate as it was higher in group A but improvement (decrement) was significant more in group A at 4 and 48 hours.

Despite we found a statistically significant drop in both SBP, and DBP, after 4 and 48 hours, but it was of no significant clinical importance. (May be due to the decreased sympathetic stimulation because of dyspnea, beside the stress of hospitalization and admission to the critical care unit). However, we used lower values of BiPAP (8-12/4-5). There- 
fore, this must be taken into consideration as the higher values, and or the hypotensive patients may get worse after BIPAP therapy.

Regarding heart rate, Inspite of a decrease in heart rate in both groups (more in group A), there was no statistically significant difference between both groups at 4 hours $(p=0.727)$ or 48 hours $(p=$ 0.099 ), and it was also of no clinical importance.

Vital and colleagues in their Cochrane Database (2008), supported the use of NIPPV versus traditional therapy in heart failure and cardiogenic pulmonary edema and showed statistically significant decreased risk of intubation, as well as decreased in-hospital mortality [9].

To our knowledge, there were few studies has been done demonstrating the effect of BIPAP on clinical, heamogasometric and echocardiographic parameters in patients with decompensated heart failure (NYHA III-IV, ACC/AHA stage C-D) due to dilated cardiomyopathy.

Brick et al., [10] have studied fourteen patients ( 9 men and 5 women) with stable chronic CHF with left ventricular ejection fraction $<35 \%$ were subjected to Bilevel positive airway pressure via nasal mask at an inspiratory pressure of $5 \mathrm{~cm} \mathrm{H} 2 \mathrm{O}$ and an expiratory pressure of $3 \mathrm{cmH}_{2} \mathrm{O}$ on spontaneous mode at room air for $1 \mathrm{~h}$. Baseline clinical and echocardiographic parameters were compared with the same parameters after $1 \mathrm{~h}$ of bilevel positive airway pressure. Statistically significant decreases were noted in these mean values: Systolic BP $(p<0.008)$, heart rate $(p<0.002)$, respiratory rate $(p<0.001)$, and systemic vascular resistance $(p<0.001)$. Statistically significant increaseswere noted in these mean values: Cardiac output from 5.09 to $6.37 \mathrm{~L} / \mathrm{min}$ ( $p 50.004)$, ejection fraction from $28.71 \%$ to $34.36 \%(p<0.001)$, and enddiastolic volume from 224.36 to $246.21 \mathrm{~mL}$ ( $p<$ $0.045)$. And this correlate with our results.

On the other hand, Levitt et al., [11] enr- olled 38 patients who were in severe CHF. Patients were randomized to receive either $\mathrm{BiPAP}$ or $\mathrm{O}_{2}$ therapy in addition to adjunct therapy. Heart rate, systolic blood pressure, diastolic blood pressure, respiratory rate were recorded at $30 \mathrm{~min}, 60 \mathrm{~min}$, and $120 \mathrm{~min}$ for all patients, the $\mathrm{ABG}$ was obtained at $60 \mathrm{~min}$ and $120 \mathrm{~min}$ after the baseline ABG. Age and gender were not different between the groups. Heart rate, systolic blood pressure, diastolic blood pressure, respiratory rate, and pulse oximetry all showed no statistically significant difference in change over time between both groups, but there was a statistically significant change over time within each group including intubation rate and AMI frequency but he didn't told about inclusion and exclusion criteria of his patients as well as the setting and mode of BIPAP which was used.

Despite the most of other studies were carried out in patients with cardiogenic pulmonary edema and the difference between BIPAP and CPAP in this setting, most of them agree with our results as regard clinical, heamdynamic effects eg [12-18]

The more advancement in technology, solved some problems related to the use of BIPAP, In the past with CPAP, facial skin necrosis with prolonged use was considered a problem; however, with soft mask cushions and stoma paste, this is no longer a problem. BiPAP can also be applied nasally, with a specially configured, smaller mask. This improves patient comfort and allows greater ease of access for clearing airway secretions. CPAP requires a very cooperative patient and loses much of its effectiveness whenever a significant mask leak is present. BiPAP, however, is more leak tolerant and therefore can be used in less cooperative patients with better results and for longer periods. With all NIV modalities, the patient controls the tidal volume and breathing frequency; despite, newer BiPAP delivery devices have highly sensitive, flow triggered inspiratory valves that reduce both the patient effort and the time from breath initiation to the delivery of assistance.

IN our study, there were still, some obstacles related to the availability of the recent devices, the low personal experience with the use of BiPAP, the small number of the patient, and the study of the chronic effects of the long term use of those category of patients necessities the need for more further studies to be done.

\section{Conclusion:}

We concluded that the use of Non-Invasive Bilevel Positive Airway Pressure ventilation with the standard medical treatment significantly improved Clinical, respiratory, with a limited hemodynamic effects, in patients with decompensated heart failure due to dilated cardiomyopathy, more than the use of the usual oxygen therapy plus the standard medical therapy with no significant differences concerning morbidity and mortality rates.

The cooperation between different health care providers such as the internal medicine physicians, emergency medicine-physicians, intensivists, respiratory therapists, and well-trained nursing staff together will improve the service and help better 
management for the critically ill patients such as those with decompensated heart failure and dilated cardiomyopathy.

Lastly, we concluded that, "BiPAP is not only a safe adjuvant to the conventional treatment but also; it can be more advantageous in the management of patients with dilatedcardiomyopathy with decompensated heart failure".

\section{References}

1- SANDRIGO MANGINI1, PHILIPPE VIEIRA PIRES2, FABIANA GOULART MARCONDES BRAGA3 and FERNANDO BACAL1 : Decompensated heart failure (Insuficiência cardíaca descompensada), Can. J. Cardiol., 24 (Suppl B): 9B-14B, 2008.

2- BOCCHI E.A., VILAS-BOAS F., PERRONE S., CAAMAÑO A.G., et al.: Latin American Guidelines for the Assessment and Management of Decompensated Heart Failure Arq. Bras.Cardiol., 85 (Suppl 3): 49-94, 1-48. 2005.

3- DE LUCA L., FONAROW G.C., ADAMS Jr. K.F., MEBAZAA A., TAVAZZI L., SWEDBERG K., et al.: Acute Heart failure syndromes: Clinical scenarios and pathophysiologic targets for therapy. Heart Fail. Rev., 12 (2): 97-104, 2007.

4- POULTON E.P. and OXON D.M.: Left sided heart failure with pulmonary).edema: Its treatment with the "pulmonary plus pressure machine.” Lancet 981-983, 1936.

5- NAUGHTON M.T., RAHMAN A., HARA K. and ET A.L.: Effect of continuous positive airway pressure on intrathoracic and left ventricular transmural pressures in patients with congestive heart failure. Circulation, 91 : 1725-1731, 1995.

6- EDWARD A. PANACEK, M.D., MPH and J. DOUGLAS KIRK, M.D. : Role of Noninvasive Ventilation in the Managementof Acutely Decompensated Heart Failure. Rev. Cardiovasc. Med., 3 (Suppl 4): S35-S40, 2002.

7- The Criteria Committee of the New York Heart Association. Nomenclature and Criteria for Diagnosis of Diseases of the Heart and Great Vessels. 9th ed. Boston, Mass: Little, Brown \& Co: 253-256, 1994.

8- YANCY C.W., et al.: "2013 ACCF/AHA Guideline for the Management of Heart Failure: A Report of the American College of Cardiology Foundation/American Heart
Association Task Force on Practice Guidelines”. Circulation 128. 16: n. pag. Print, 2013.

9- VITAL F.M., SACONATO H., LADEIRA M.T., et al.: Noninvasive positive pressure ventilation (CPAP or bilevel NPPV) for cardiogenic pulmonary edema. Cochrane Database Syst. Rev. (3): CD005351, 2008.

10- BRICK ACOSTA, M.D.; ROBERT DIBENEDETTO, M.D., F.C.C.P.; ALI RAHIMI, M.D., et al.: Hemodynamic Effects of Noninvasive Bilevel Positive Airway Pressure on Patients with Chronic Congestive Heart Failure with Systolic Dysfunction Chest, 118: 1004-1009, 2000.

11-LEVITT M.A.: A prospective, randomized trial of BiPAP in severe acute congestive heart failure. J. Emerg. Med. Nov., 21 (4): 363-9, 2001.

12- PARK LAPINSKY S.E., MOUNT D.B., MACKEY D., et al.: Management of acute respiratory failure due to pulmonary edema with nasal positive pressure support. Chest, 105: 229-3 1, 1994.

13- MEHTA S., JAY G.D., WOOLARD R.H., et al.: Randomized, prospective trial of bilevel versus continuous positive airway pressure in acute pulmonary edema. Crit. Care. Med., 25: 620-8, 1997.

14- RUSTERHOLTZ T. , KEMPF J., BERTON C., et al.: Noninvasive pressure support ventilation (NIPSV) with face mask in patients with acute cardiogenic pulmonary edema. Intensive Care. Med., 25: 21-8, 1999.

15- JOSEF MASIP J., BETBESE A.J., PAEZ J., et al.: Noninvasive pressure support ventilation versus conventional oxygen therapy in acute cardiogenic pulmonary oedema: A randomized trial. Lancet, 356: 2126-32, 2000.

16- NAVA S., CARBONE G., DIBATTISTA N., et al.: Noninvasive ventilation in cardiogenic pulmonary edema: A multicenter randomized trial. Am. J. Respir Crit. Care. Med., 168: 1432-7, 2003.

17- AKIKO NODA, Ph.D.; HIDEO IZAWA, M.D., Ph.D.; HIROYUKI ASANO, M.D., et al.: Beneficial Effect of Bilevel Positive Airway Pressure on Left Ventricular Function in Ambulatory Patients With Idiopathic Dilated Cardiomyopathy and Central Sleep Apnea-Hypopnea* A Preliminary Study. Chest, 131: 1694-1701, 2007.

18- RAMI N. KHAYAT, M.D., F.C.C.P., WILLIAM T. ABRAHAM, M.D., BRIAN PATT, B.S., et al.: Cardiac Effects of Continuous and Bilevel Positive Airway Pressure for Patients With Heart Failure and Obstructive Sleep Apnea. Chest December, 134 (6): 1162-1168. doi:10. 1378/chest.08-03 46, 2008. 


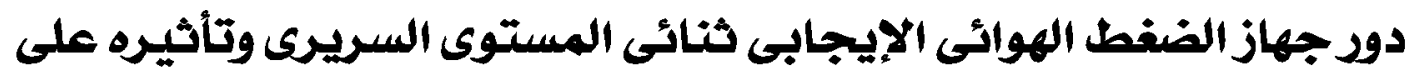

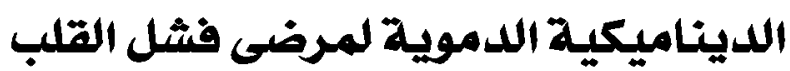

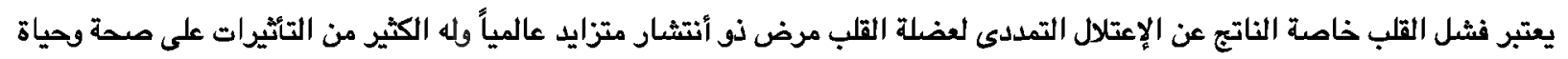

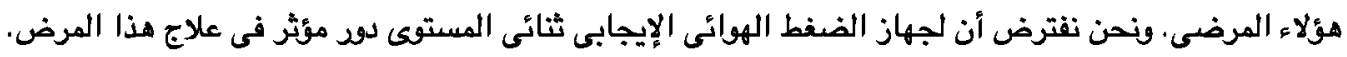

الهدف: دراسة تأثير ودود جهاز الضفط الهوائى الإيجابى ثنائى المستوى على الحالة السريرية والديناميكية الدموية فى مرضى فثل القلب الدرجة الثالثة والرابعة بتقسيم جمعية نيويورك لقلب.

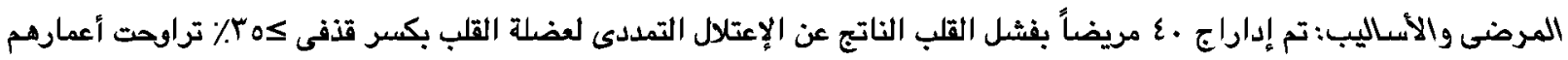

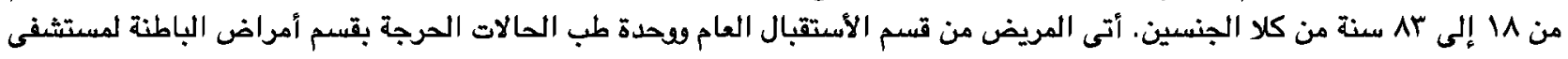

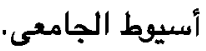

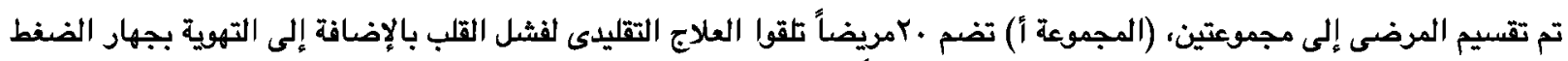

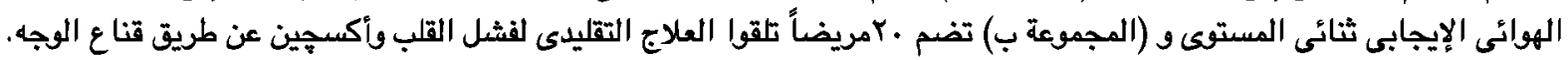

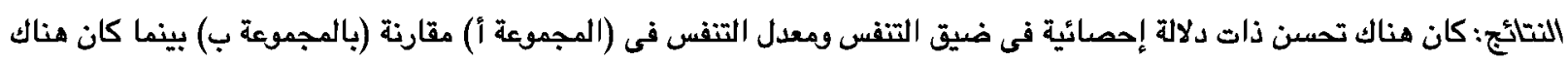

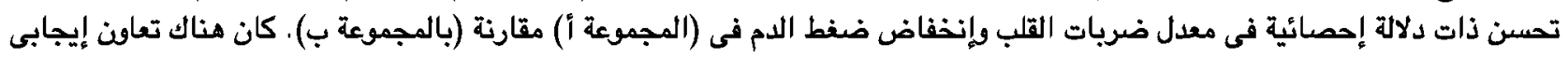

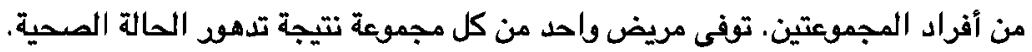

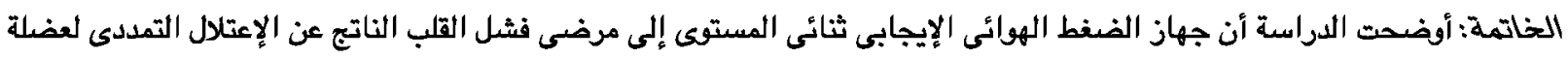

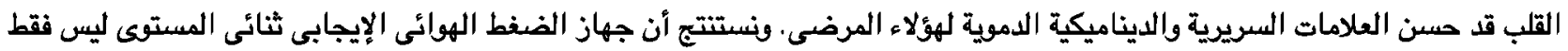

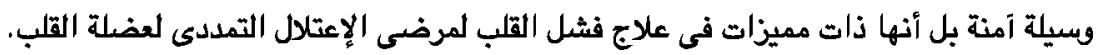

